\title{
“NOBILISSIMA PICTURAE PURPUREAE”: I FUNERALI DEL RE CARLO I D'UNGHERIA (1342) E LA PROIEZIONE DEL POTERE MONARCHICO NEL TARDO MEDIOEVO
}

\author{
Vinni Lucherini
}

\author{
V. Lucherini \\ Dipartimento di Studi Umanistici \\ Università degli Studi di Napoli Federico II \\ Napoli, Italia
}

\begin{abstract}
This article analyses a description of the funerary ceremonies of Charles I of Hungary held on the days following his death on $16^{\text {th }}$ July 1342. The description is contemporary to the events although it is only known through Hungarian chronicles of the $15^{\text {th }}$ century. It is a document of great importance for the study of medieval rituals. The king's face was left bare for all the duration of the funeral. His cadaver was dressed up with a scarlet cloak, crowned in gold and buried in a marble tomb next to the remains of saint-kings Stephen and Emeric in the same church where he was crowned in 1310. Funerary rites emphasized the dead's kingship in a solemn display stressing his chivalry virtues and the legitimation of his succession.
\end{abstract}

Key words: Kingdom of Hungary, King Charles I, Medieval and Humanistic Chronicles, Rites of Power

Il 16 luglio 1342 moriva a Visegrád il re Carlo I d'Ungheria'. Nato nel 1288 nel seno della famiglia reale di origine capetingia che fin dalla metà del Duecento aveva governato il Regnum Sicilice, feudo della Chiesa di Roma; nipote del re Carlo II d'Angiò e della regina Maria d'Ungheria², in quanto figlio primogenito di Carlo Martello, il giovane principe le cui speranze di diventare re di Sicilia e d'Ungheria

\footnotetext{
* Questo articolo, che dedico a Igor Fisković con il quale ho avuto il piacere di discutere più volte in Croazia alcuni dei temi qui in esame, trae origine da una più ampia indagine sulle relazioni tra Napoli e l'Ungheria durante il Medioevo avviata nell'anno accademico 2011-2012 con il supporto dell'Institute for Advanced Study della Central European University di Budapest. Il contributo rientra nel quadro del progetto Croatian Medieval Heritage in European Context: Mobility of Artists and Transfer of Forms, Functions and Ideas (6095, CROMART), finanziato dalla Fondazione Croata delle Scienze (2014-2018). Mi si consenta di citare nelle note le pubblicazioni, già apparse o ancora in corso di stampa, pertinenti a questa ricerca, dalle quali si potranno trarre i principali riferimenti alla bibliografia e alla storiografia novecentesca, soprattutto ungherese, qui per brevità omesse.

${ }^{1}$ Sul regno di Carlo I (1310-1342) e su questa fase della storia ungherese: B. HÓMAN, Gli Angioni di Napoli in Ungheria, Roma, 1938; G. KRISTÓ, Les bases du pouvoir royal de Charles Ier en Hongrie, in: La noblesse dans les territoires angevins à la fin du Moyen Âge, sous la direction de N. COULET et J.-M. MATZ, Roma, 2000, pp. 423429; P. ENGEL, The Realm of St Stephen. A History of Medieval Hungary 895-1526, translated by T. PÁLOSFALVI, edited by A. AYTON, London, 2001, in part. pp. 124-130; P. MOLNÁR, Idéologies monarchiques en Hongrie (XII$I^{e}$-XIVe siècle), in: Identités hongroises, identités européennes du Moyen Âge à nos jours, sous la direction de P. NAGY, Mont-Saint-Aignan, 2001, 23-47; L'Ungheria angioina, a cura di E. CSUKOVITS, Roma, 2013; e il fascicolo della Hungarian Historical Review. New Series of Acta Historica Academice Scientiarum Hungarice, 2/2 (2013), dedicato alla Angevin History. Per i documenti relativi a questo periodo, con particolare riferimento al rapporto del Regno d'Ungheria con il Regno di Sicilia: Monumenta Hungarice Istorica. Diplomacziai emlékek az Anjou-Korból, I, edited by G. WENZEL, Budapest, 1874.

${ }^{2}$ V. LUCHERINI, Il "testamento" di Maria d'Ungheria a Napoli: un esempio di acculturazione regale, in: Images and Words in Exile, edited by E. BRILLI, L. FENELLI and G. WOLF, Firenze, 2015, pp. 433-450.
} 


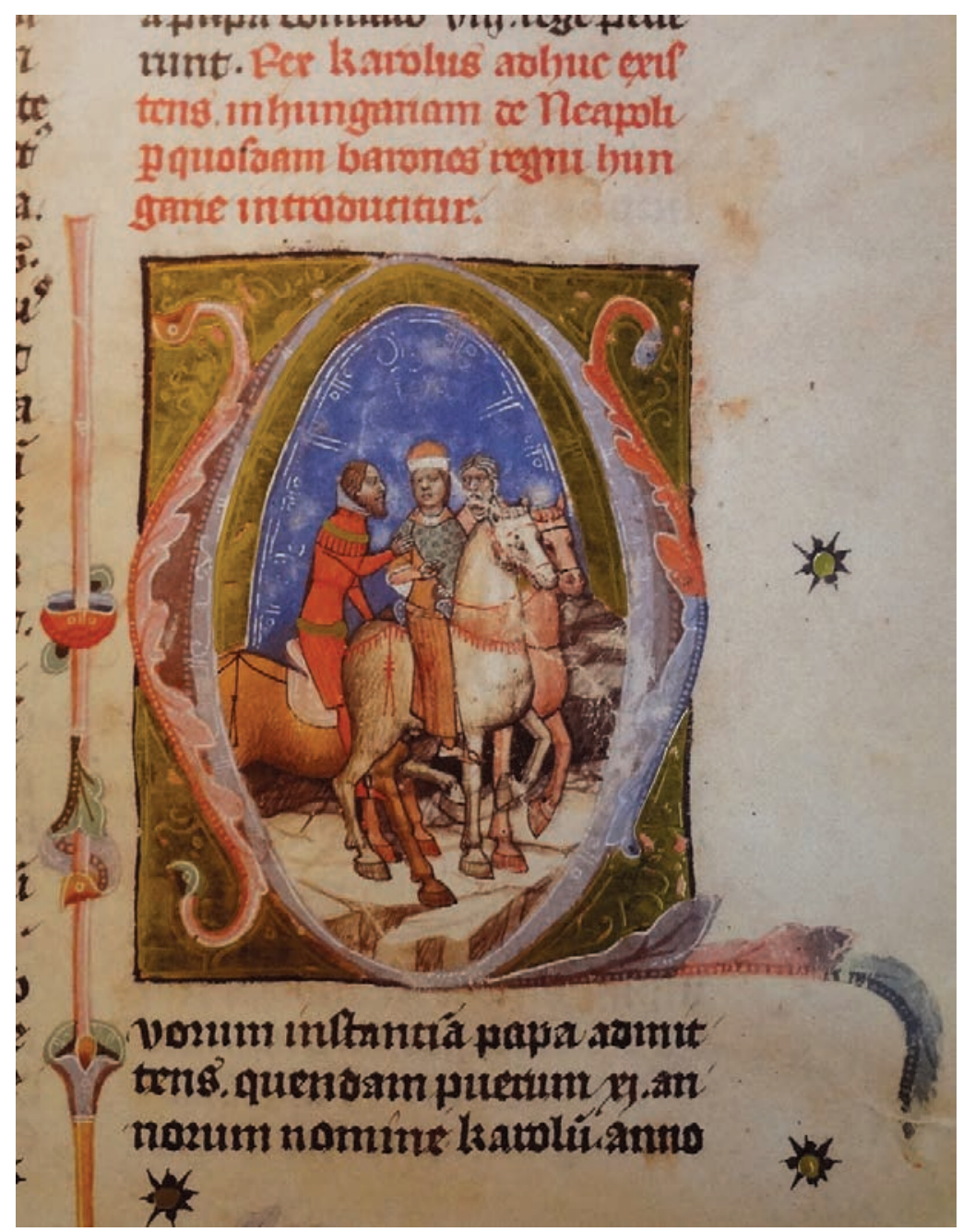

Fig. 1. Budapest, Országos Széchényi Könyvtár, Clmae 404, Chronicon pictum, fol. 66r, Arrivo di Carlo I in Ungheria.

furono spezzate prematuramente ${ }^{3}$; partito da Napoli ancora bambino (fig. 1) per prendere possesso del trono ungherese rimasto vacante a séguito di un lungo periodo di lotte intestine e di anarchia, Carlo I, che i napoletani chiamavano Caroberto, era stato incoronato rex Hungarice ad Alba Reale (Székesfehérvár) il 27 agosto $1310^{4}$, con la sacra corona ritenuta di santo Stefano ${ }^{5}$. Al pari dei suoi

${ }^{3}$ C. MINIERI RICCIO, Genealogia di Carlo II d'Angiò re di Napoli, in Archivio Storico per le Province Napoletane, 7 (1882), pp. 15-67; M. SCHIPA, Carlo Martello, in Archivio Storico per le Province Napoletane, XIV (1889), pp. 17-33, 204-264, 432-458; XV (1890), pp. 5-125.

${ }^{4}$ Sulle incoronazioni dei re d'Ungheria: E. FÜGEDI, Coronation in Medieval Hungary, in: Studies in Medieval and Renaissance History, II (1980), pp. 159-189; e più in generale, Coronation, Medieval and Early Modern Monarchic Ritual, edited by J. M. BAK, Berkeley-Los Angeles, 1990.

${ }^{5}$ T. VON BOGYAI, Über die Forschungsgeschichte der heiligen Krone, in: Insignia Regni Hungarice. I. Studien zur Machtsymbolik des Mittelalterlichen Ungarn, edited by Zs. LOVAG, Budapest, 1983, pp. 65-89; E. TÓTH, K. SZELÉNYI, Die heilige Krone von Ungarn. Könige und Krönungen, Budapest, 1996; A Thousand Years of Christianity in Hungary, edited by I. ZOMBORI, P. CSÉFALVAY and M. A. DE ANGELIS, Budapest, 2001, pp. 266-268; La Sainte Couronne de Hongrie, numero monografico degli Acta Historice Artium, XLIII (2002), pp. 3-111; V. LUCHERINI, La prima descrizione moderna della corona medievale dei re d'Ungheria: il De sacra corona di Péter Révay (1613), in: Ars auro gemmisque prior. Mélanges en hommage à Jean-Pierre Caillet, a cura di M. JURKOVIĆ et alii, Zagreb, 2013, pp. 479-490. Sull'uso politico di questo oggetto, ora conservato nel Palazzo del Parlamento di Budapest: L. PÉTER, The Holy Crown of Hungary, Visible and Invisible, in The Slavonic and East European Review, LXXXI (2003), pp. 421-510. 


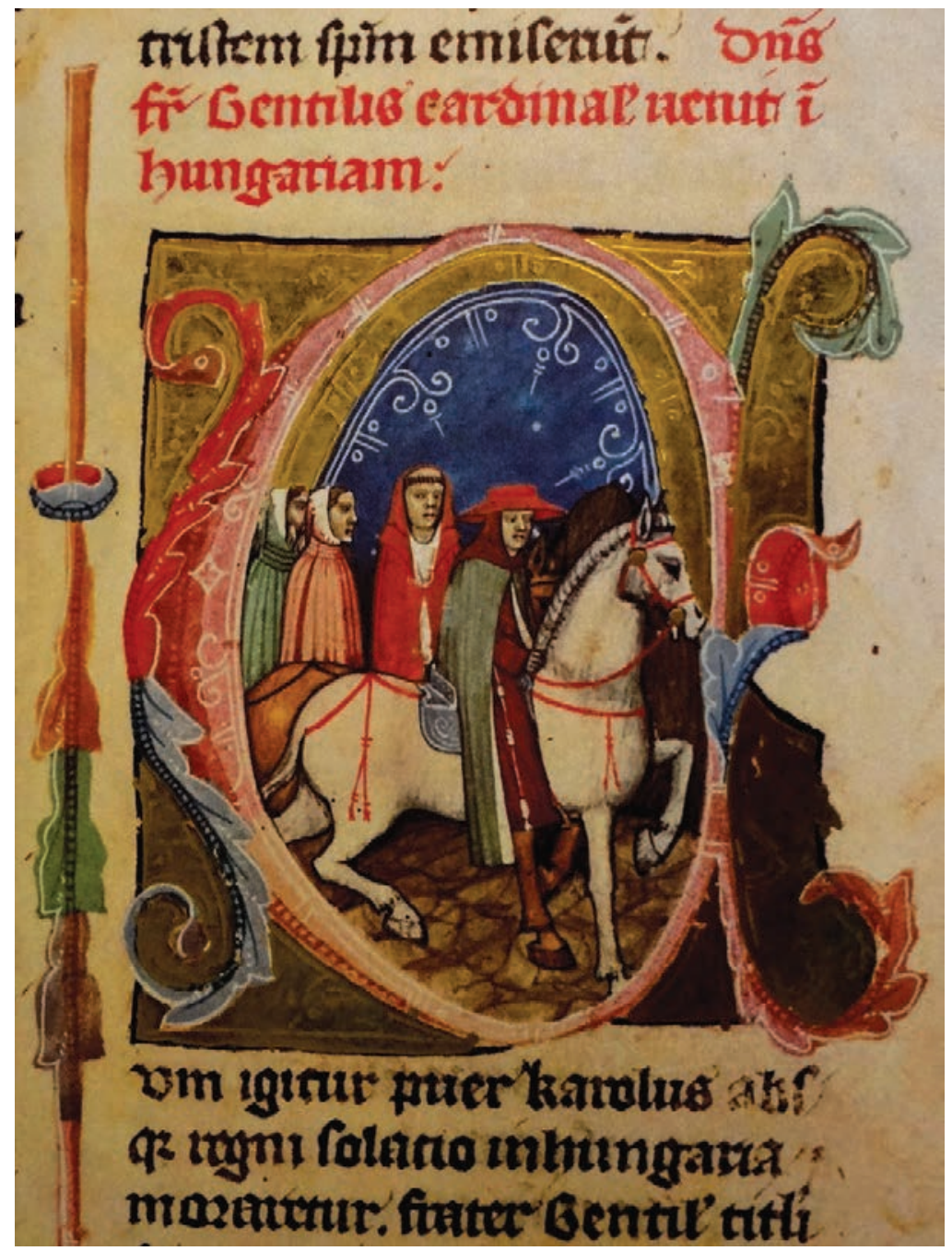

Fig. 2. Budapest, Országos Széchényi Könyvtár, Clmae 404, Chronicon pictum, fol. 68v, Arrivo di Gentile Partino di Montefiore in Ungheria.

predecessori e successori ungheresi, al pari dei suoi omologhi napoletani e francesi, anche questo re si servì di un efficace apparato simbolico, fondato sulle immagini e sui rituali solenni, per proiettare visivamente la natura del proprio potere ${ }^{6}$.

Le fonti testuali ungheresi consentono di tracciare un quadro molto netto delle modalità con cui si svolsero i principali episodi legati alla sua vita e alla sua morte. I documenti redatti dal cardinale

\footnotetext{
${ }^{6}$ P. BOURDIEU, Les rites comme actes d'institution, in Actes de la recherche en sciences sociales, XLIII (1982), pp. 58-63; Rites of Power. Symbolism, Ritual and Politics since the Middle Ages, edited by S. WILENTZ, Philadelphia, 1983; Ritual of Power from Late Antiquity to the early Middle Ages, edited by F. THEUWS and J. L. NELSON, Leiden, 2000; G. ALTHOFFS, Die Macht der Rituale. Symbolik und Herrschaft im Mittelalter, Darmstadt, 2003; Die Kultur des Rituals, Inszenierungen, Praktiken, Symbole, hrsg. von C. WULF und J. ZIRFAS, München, 2004; Investitur- und Krönungsrituale. Herschaftseinsetzungen im kulturellen Vergleich, hrsg. von M. STEINICKE und S. WEINFURTER, Köln, 2005. Per quanto riguarda Carlo I d'Ungheria: V. LUCHERINI, L'arte alla corte dei re "napoletani" d'Ungheria nel primo Trecento: un equilibrio tra aspirazioni italiane e condizionamenti locali, in: Arte di Corte in Italia del Nord. Programmi, modelli, artisti (1330-1402 ca.), a cura di S. ROMANO e D. ZARU, Roma, 2013, pp. 371-396. Sull'uso delle immagini da parte dei diversi tipi di poteri nel tardo Medioevo si vedano ora gli atti del convegno internazionale Performing Power through Visual Narratives in Late Medieval Europe: an Interdisciplinary Approach (International Research Center for Late Antiquity and Middle Ages - Zagreb, Poreč, 29-31 May 2014), edited by M. JURKOVIĆ and V. LUCHERINI, in Hortus artium medievalium, XXI (2015), pp. 6-300.
} 
francescano Gentile Partino di Montefiore ${ }^{7}$, incaricato dal papa Clemente V di recarsi in Ungheria in missione diplomatica nell'agosto del 1307 (fig. 2) per risolvere in favore di Carlo I la questione della successione al trono d'Ungheria, illustrano a chiare lettere la sequenza e persino il valore dei gesti compiuti in occasione della consacrazione del re, la posizione e il ruolo dei regalia, le parole pronunciate dai diversi protagonisti dell'evento ${ }^{8}$. A loro volta, le cronache tardo-quattrocentesche, sicuramente basate su testi più antichi purtroppo perduti, hanno tramandato un puntuale resoconto del funerale di Carlo I e della sua sepoltura, ponendosi come un documento di grande rilievo sul comportamento del potere medievale di fronte alla morte ${ }^{9}$, tanto più importante se si considera la rarità di fonti di questo genere per il tardo Medioevo europeo.

\section{LE CRONACHE UMANISTICHE UNGHERESI E LA MORTE DI CARLO I}

Non restano testimonianze di prima mano che raccontino quanto accadde sùbito dopo la morte di Carlo I, e l'unico codice trecentesco miniato che tramanda l'intera storia d'Ungheria fino all'epoca di questo re, il cosiddetto Chronicon pictum custodito nella Biblioteca Nazionale di Budapest (ms. Clmae 404), commissionato nel 1358 dal re Ludovico il Grande (figlio ed erede di Carlo I), si arresta bruscamente al 1330, con il racconto della guerra contro il vovoida transilvano Bazarad ${ }^{10}$. La più antica attestazione conservatasi si rinviene invece nella Chronica Hungarorum pubblicata in folio minore a Buda dal tipografo Andreas Hess, il 5 giugno 1473, priva di titolo e con una dedica a László Kárai, preposto della Chiesa di Buda e vicecancellario del re Mattia Corvino. Il testo, chiamato dai successivi editori Chronicon Budense per il luogo della sua prima apparizione a stampa (non se ne conservano esemplari manoscritti anteriori), costituisce un assemblaggio di fonti cronachistiche di diversa natura e datazione che copre circa dieci secoli, dalle origini del popolo ungherese fino all'anno 1468, cioè al ritorno di Mattia Corvino dalla campagna moldava ${ }^{11}$. Il regno di Carlo I vi è narrato minuziosamen-

\footnotetext{
${ }^{7}$ É. HORN, La mission diplomatique d'un franciscain, in Études franciscaines, XXXVII (1925), pp. 405-418; Monumenta Vaticana historiam Regni Hungarice illustrantia. Serie prima. Tomus secundus. Acta legationis cardinalis Gentilis. 1307-1311, edited by A. VÁRSZEGI and I. ZOMBORI, Budapest, 2000.

${ }^{8}$ Per l'analisi dei documenti relativi al cerimoniale di incoronazione di Carlo I: V. LUCHERINI, Raffigurazione e legittimazione della regalità nel primo Trecento: una pittura murale con l'incoronazione di Carlo Roberto d'Angiò a Spišská Kapitula (Szepeshely), in: Medioevo: natura e figura, Atti del convegno internazionale (Parma, 20-25 settembre 2011), a cura di A. C. QUINTAVALLE, Milano, 2015, pp. 675-687.

${ }^{9}$ Sui rituali funebri: Ph. ARIÈS, Essais sur l'histoire de la mort en occident, du Moyen Age à nos jours, Parigi, 1975; R. C. FINUCANE, Sacred Corpse, Profane Carrion: Social Ideals and Death Rituals in the Later Middle Ages, in: Mirrors of Mortality. Studies in the Social History of Death, edited by J. WHALEY, Abingdon, 2011 (I ed. 1981); pp. 40-60; P. METCALF, R. HUNTINGTON, Celebration of Death. The Anthropology of Mortuary Ritual, Cambridge, 1991; P. BINSKI, Medieval Death. Ritual and Representation, London, 1996; M. GAUDE-FERRAGU, D'or et de cendres. La mort et les funérailles des princes dans le royaume de France au bas Moyen Âge, Villeneuve d'Ascq, 2005; Les funérailles princières en Europe, XVIe-XVIII siècle. 1. Le grand théâtre de la mort, sous la direction de J. A. CHROŚCICKI, M. HENGERER et G. SABATIER, Versailles, 2012; Un gallo ad Asclepio. Morte, morti e società tra antichità e prima età moderna, a cura di A. L. TROMBETTI BUDRIESI, Bologna, 2013. Sul corpo: J. LE GOFF, Une histoire du corps au Moyen Âge, en collaboration avec N. TRUONG, Paris, 2003; Il cadavere. The corps, in Micrologus, VII (1999); Le corps du prince, Actes du colloque (Liège, 17-19 novembre 2011), Firenze, 2014.

${ }^{10}$ Tra l'ampia bibliografia: The Hungarian Illuminated Chronicle, edited by D. DERCSÉNYI and others, with a translation by A. WEST, Budapest, 1969; L. VEZPRÉMY, T. WEHLI, J. HAPÁK, The Book of the Illuminated Chronicle, Budapest, 2009; più di recente, V. LUCHERINI, Il Chronicon pictum ungherese (1358): racconto e immagini al servizio della costruzione dell'identità nazionale, in Rivista di Storia della Miniatura, 19 (2015), pp. 58-72. Solo un riferimento sintetico alla morte di Carlo I si rinviene nel Chronici Hungarici compositio sceculi XIV, dove si dice che Carlo I morì nel castello di Visegrád, dove viveva, e che fu sepolto "in Albensi ecclesia": Chronici Hungarici Compositio Saeculi XIV, praefatus est, textum recensuit, annotationibus instruxit A. Domanovszky, in E. SZENTPÉTERY, Scriptores rerum Hungaricarum tempore ducum regumque Arpadiance gestarum, Budapest, 1937, p. 502.

${ }^{11}$ Chronicon Budense, post elapsos ab editione prima et rarissima tercentos sexaginta quinque annos secundam adornavit, textum recognovit, notis illustravit, lemmata ac indices adiecit, et prefatus est Iosephus Podhradczky [...], Budæ, 1838.
} 
te, in perfetto parallelismo con il racconto del Chronicon pictum ${ }^{12}$, ma con l'aggiunta di episodi che nella fonte trecentesca mancavano, come il resoconto del viaggio a Napoli che il re fece nel $1333^{13}$, l'incontro con i re di Polonia e Boemia nel 1335, o appunto la morte e i funerali del re.

Analoga sequenza di fatti e una narrazione quasi interamente sovrapponibile si riscontra, per queste stesse vicende, nella Chronica Hungarorum di János Thuróczy, che apparve a stampa nel 1488 prima a Brno, con il titolo Illustrissimorum regum Hungarice chronica, pubblicata da Konrad Stahel e Matthias Preinlein, e poi ad Augsburg, poco più di due mesi dopo, con il titolo Serenissimorum Hungarice regum chronica, pubblicata dal tipografo Erhard Ratdolt con il supporto del cittadino di Buda Theobald Feger, un libraio di origine tedesca che dedicò il libro a Mattia Corvino. Thuróczy procedette attingendo alle medesime fonti medievali già usate dal compilatore del Chronicon Budense, indizio dell'esistenza di una perduta storia del regno di Carlo I che, per ragioni ormai ignote, non aveva trovato spazio nel Chronicon pictum e che non si è tramandata autonomamente, ma nella quale la morte del re e il suo funerale occupavano grande spazio.

\section{IL COMPIANTO SUL RE MORTO E IL CERIMONIALE FUNEBRE}

Nel narrare la morte di Carlo I, sia il Chronicon Budense che Thuróczy giustapposero due distinte entità testuali: il compianto funebre, pronunciato dal vescovo di Esztergom Chanád di Telegd (1330-1349) durante la tumulazione del re ad Alba Reale, e la descrizione del funerale del re, durato tre giorni ${ }^{14}$. Considerata la grande quantità di dettagli relativi al cerimoniale che furono immessi nella narrazione e la verosimiglianza retorica del compianto, il redattore di questa parte della storia ungherese, che poi appunto conflui a stampa nel Chronicon Budense e in Thuróczy, dové servirsi dì fonti contemporanee ai fatti narrati, ma non si può escludere che ne sia stato persino un testimone oculare.

Le parole del vescovo di Esztergom, che aveva conosciuto bene il re ed era stato al suo fianco durante il viaggio a Napoli nel $1333^{15}$, mettono l'accento su una figura di re molto amata e rispettata, com'era consuetudine in questo tipo di elogio. Il vescovo esordisce con un'esclamazione di dolore, alla quale fanno séguito riflessioni classiche sulla caducità della vita umana e sulla sua perenne condizione di cambiamento. Ma sùbito dopo si rivolge direttamente alla Morte, che non aveva temuto di entrare clandestina nell'inespugnabile castello di Visegrád: insaziabile nel godere di cadaveri di ogni

\footnotetext{
${ }^{12}$ Su come la storiografia umanistica ungherese guardò a questa fase della storia del regno, e sull'uso che fece delle fonti medievali: V. LUCHERINI, La genesi e gli effetti dell'asse politico napoletano-ungherese attraverso lo sguardo della storiografia quattro-cinquecentesca: temi identitari, scambi di nomini e di culture, in: Alle origini del Rinascimento in Ungheria, Atti della giornata di studi (Roma, Accademia d'Ungheria, 26 maggio 2015), in corso di stampa.

${ }^{13}$ Sui risvolti politici di quel viaggio, teso a consolidare i rapporti tra Napoli e l'Ungheria attraverso il matrimonio dei principi Giovanna d'Angiò e Andrea d'Ungheria: V. LUCHERINI, The Journey of Charles I, King of Hungary, from Visegrád to Naples (1333): Its Political Implications and Artistic Consequences, in The Hungarian Historical Review. New Series of Acta Historica Academice Scientiarum Hungarice, 2/2 (2013), pp. 341-362; EAD., Il refettorio e il capitolo del monastero maschile di Santa Chiara: l'impianto topografico e le scelte decorative, in: La chiesa e il convento di Santa Chiara. Committenza artistica, vita religiosa e progettualità politica nella Napoli di Roberto d'Angiò e Sancia di Maiorca, a cura di F. ACETO, S. D'OVIDIO ed E. SCIROCCO, Battipaglia, 2014, pp. 385-430; EAD., Precisazioni documentarie e nuove proposte sulla commissione e l'allestimento delle tombe reali angioine nella Cattedrale di Napoli, in: L'officina dello sguardo. Scritti in onore di Maria Andaloro. I luoghi dell'arte. Immagine, memoria, materia, Roma, 2014, pp. 185-192; EAD., Celebrare e cancellare la memoria dinastica nella Napoli angioina: le tombe del principe Andrea d'Ungheria e della regina Giovanna I, in Hortus artium medievalium, XXI (2015), pp. 76-91.

${ }^{14}$ Per rendere immediatamente disponibile al lettore il compianto e la descrizione del funerale di Carlo I, si propone in Appendice una trascrizione di questi testi effettuata con moderni criteri ecdotici.

${ }_{15}$ Per i partecipanti alla missione diplomatica di Carlo I a Napoli: V. LUCHERINI, The Journey cit.; per l'operato del vescovo Chanád: Archiepiscopi Strigonienses compendio dati a p. Nicolao Schmitth e Societate Jesu, pars prima editio altera, Tyrnaviæ, MDCCLVIII, pp. 180-190.
} 


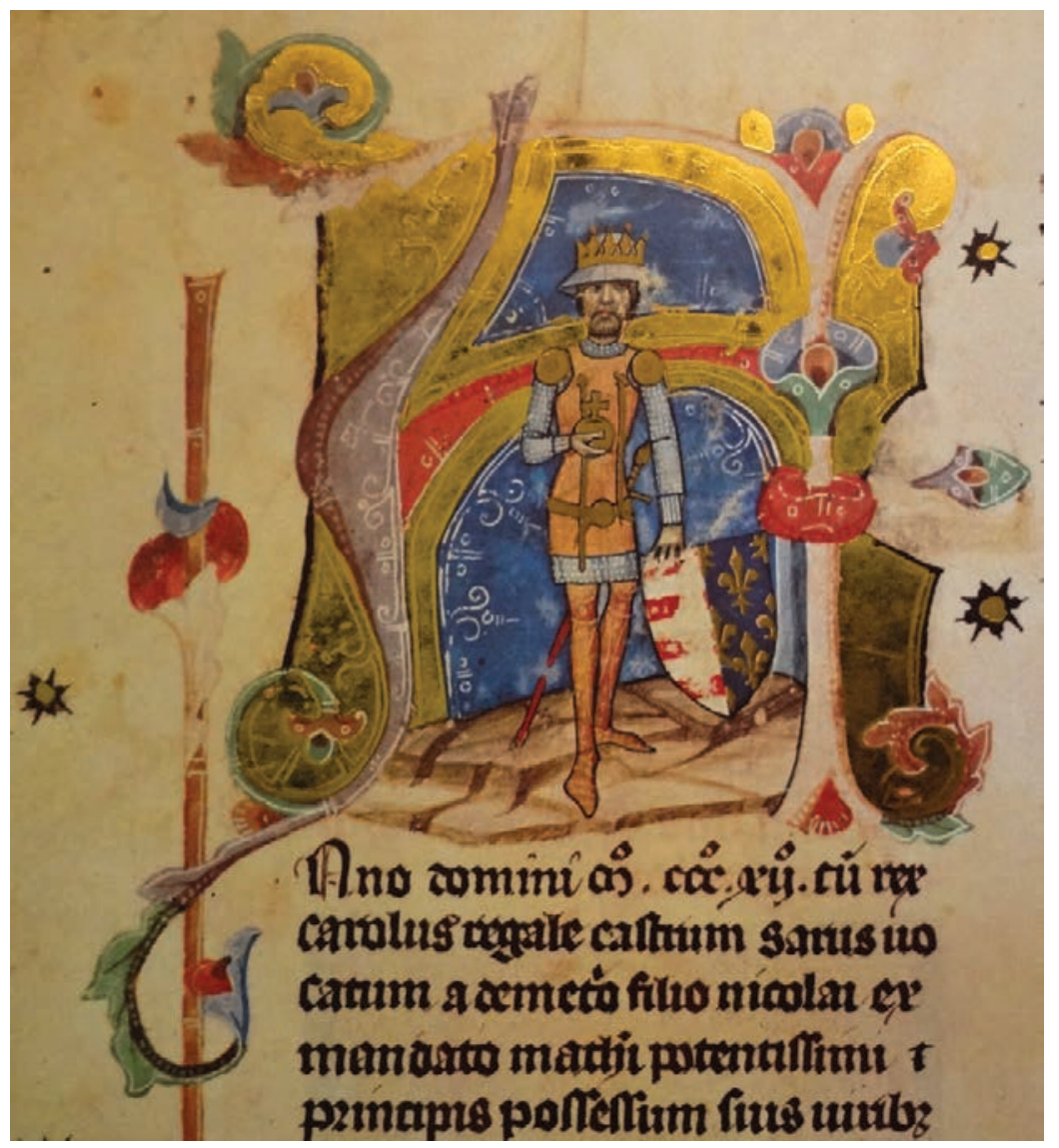

Fig. 3. Budapest, Országos Széchényi Könyvtár, Clmae 404, Chronicon pictum, fol. 69v, Carlo I con le insegne regali.

specie, rimasta indifferente di fronte ai vestiti preziosi del re, adorni di gemme, pietre e perle, tessuti d'oro e d'argento, la morte aveva sottratto l'anima di Carlo I e fatto sparire i suoi splendidi onori (fig. 3), provocando lutto e dolore in ogni abitante del regno, ma soprattutto nella regina Elisabetta, sua moglie, e in suo figlio Ludovico (fig. 4).

A questa parte fa séguito, senza soluzione di continuità, la descrizione di quanto avvenne a partire dal giorno successivo alla morte del re, vale a dire il 17 luglio 1342. Su ordine della regina Elisabetta, gli arcivescovi del regno, i vescovi, i prelati, i baroni, i presbiteri, i monaci e i chierici accompagnarono in processione il corpo del re dal castello di Visegrád alla chiesa parrocchiale della Vergine Maria. Il cadavere era stato preparato secondo quanto conveniva alla dignità del suo ruolo: sul capo "preziosissimo" portava la corona d'oro, mentre il corpo "oltremodo splendido" vestiva la clamide scarlatta, e i suoi piedi "bellissimi" le calighe intessute di gemme con i calzari d'oro.

Svoltesi le istituzioni divine e le messe solenni, il cronista racconta che re fu messo in una "cimba" e portato sul Danubio fino a Buda: lo precedevano i prelati, i baroni e gli altri regnicoli (secondo l'ordine più frequente nei funerali reali tardo-medievali), con il famoso soldato Lorenzo Sclavo reggente i vessilli, come sempre aveva fatto quando il re era in vita. Giunti a Buda nel luogo convenuto, vi trovarono tutta la cittadinanza, i sacerdoti, i chierici, accorsi con i vestiti funebri per rendere omaggio al re defunto e scortarlo nella città. Per tutta la notte si innalzarono preghiere e canti, e il giorno dopo, il 18 luglio, si svolsero i divini uffici e misteri, oltre che le messe solenni.

Davanti alle porte della chiesa (non si specifica quale, ma si deve intendere la chiesa di Buda dedicata alla Vergine) si vedevano immobili i tre grandi destrieri del re, ricoperti di ornamenti purpurei. Su di essi sedevano tre soldati, vestiti delle insegne reali (vale a dire lo scudo angioino-arpadiano partito nella destra araldica de Hongrie ancien, fascé de gueles et d'argent, e nella sinistra araldica 


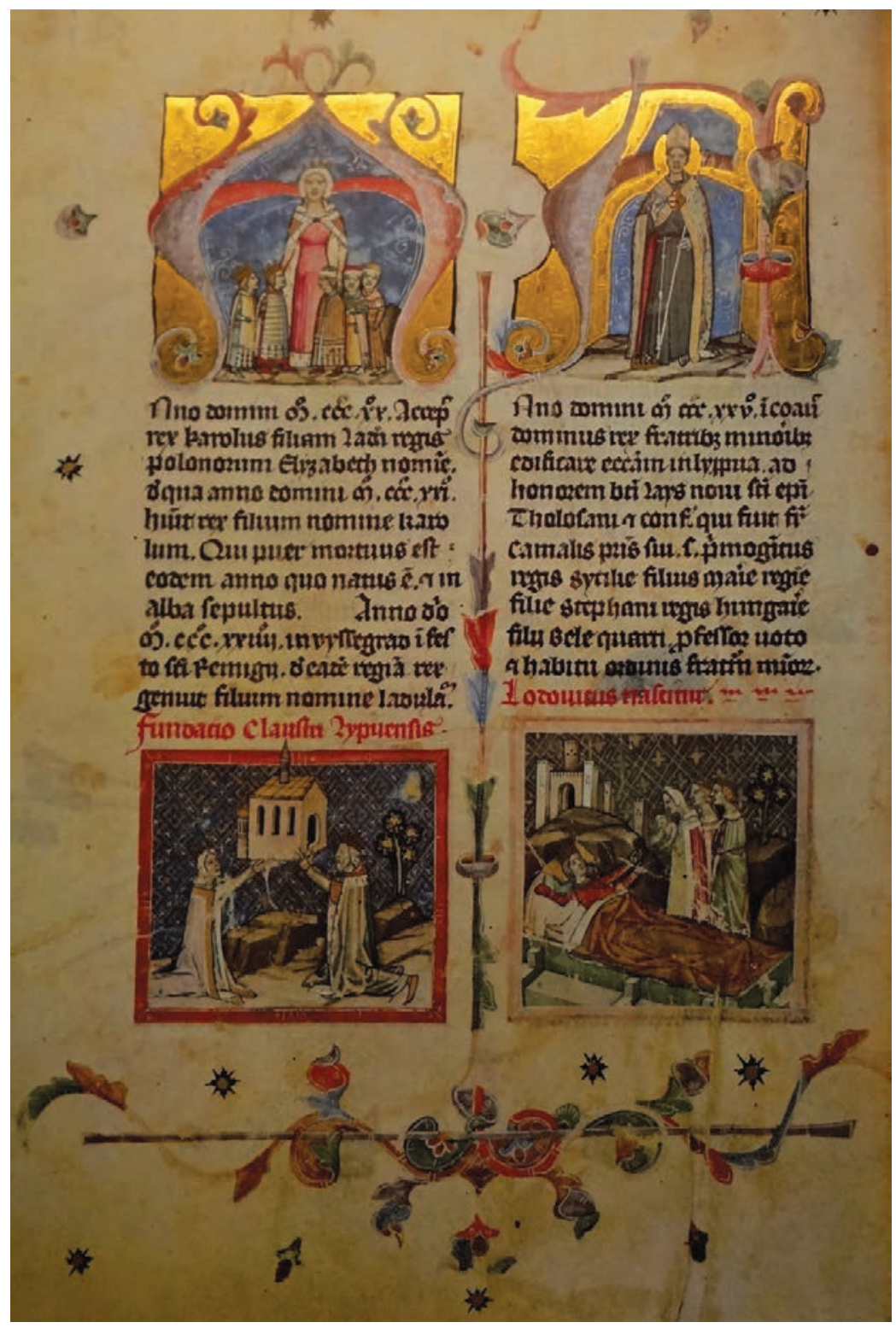

Fig. 4. Budapest, Országos Széchényi Könyvtár, Clmae 404, Chronicon pictum, fol. 70v, Episodi della vita di Carlo I e di Elisabetta alludenti alla genealogia della dinastia reale napoletano-ungherese.

d'azur semé de fleurs de lys d'or): il primo era decorato con le armi da torneo, convenienti alla regia eccellenza ${ }^{16}$; il secondo con quelle per il gioco di lancia; il terzo con le armi di guerra, ugualmente pertinenti alla regia maestà. Le insegne dei soldati recavano anche gli elmi d'oro coronati con la forma dello struzzo, simbolo araldico che lo stesso Carlo I aveva prescelto per il suo blasone ${ }^{17}$. Le

\footnotetext{
${ }^{16}$ Sui tornei medievali: R. BARBER, J. BARKER, Tournaments, Jousts. Chivalry and Pageants in the Middle Ages, Woodbridge, 1989.

${ }^{17}$ L'insegna con lo struzzo fa la sua comparsa, con diverse varianti, sulle monete di Carlo I negli anni venti del Trecento: L. RÉTHY, Corpus nummorum Hungarice-Magvar egyetemes éremtár, II, Budapest, 1907, pp. 7, 31, 38, 46; Sz. DE VAJAY, L'héraldique image de la psychologie sociale: quelques problèmes el'héraldique royale des Angevins hongrois, in Atti dell'Accademia Pontaniana, n. s. 16 (1967), pp. 39-53. Ludovico il Grande lo usò nei suoi sigilli anulari e nel sigillo segreto impiegato dal 1358 fino alla morte, e non a caso il cimiero con lo struzzo fu miniato anche nel bas-de-page del frontespizio del Chronicon pictum: Gy. RÁCZ, L'araldica dell'età angioina, in: L'Ungheria angioina, cit., pp. 283-318, con i riferimenti alla principale bibliografia ungherese precedente.
} 
spade, così come le staffe dei cavalli, le redini, le corregge, i freni, erano stati fabbricati in argento dorato, sempre secondo quanto era opportuno alla regia eccellenza, così come intessute di seta erano le selle e le avanselle.

Svoltesi le messe solenni, le spoglie del re furono condotte alla città di Alba Reale per essere tumulate. Durante il viaggio da Buda, il volto e il corpo del re non furono celati, secondo la consuetudine degli altri re ungheresi, ma furono mostrati apertamente ai presenti. Dovunque passava, lungo il percorso, risuonavano i lamenti della popolazione accorsa a piangere il sovrano defunto. Tutta la notte i sacerdoti e i chierici cantarono inni e salmi. Fattosi giorno (siamo ormai al 19 luglio), cominciarono i divini uffici e le messe solenni, e finché durarono, i tre destrieri con i loro superbi cavalieri rivestiti delle insegne del re restarono davanti alle porte della chiesa della Vergine di Alba Reale, dove, terminate le celebrazioni, il re fu seppellito accanto all'altare maggiore, nel quale già si trovavano le reliquie dei re-santi Stefano ed Emerico ${ }^{18}$ : le lacrime impregnarono le pietre marmoree. Fu soltanto a questo punto, con il corpo di Carlo I chiuso nella sua tomba, che il vescovo Chanád di Esztergom pronunciò la sua orazione funebre, che le edizioni tardo-quattrocentesche pongono graficamente prima della descrizione del funerale, in una poco riuscita operazione di sartoria testuale: la fine del compianto si trova infatti dopo il resoconto della tumulazione e prima dell'elenco delle donazioni fatte alla chiesa di Alba Reale (da "Attamen non mirum" a "in die illa surrectum in ipso"). A questo elenco, che il redattore cita sommariamente per non tediare il lettore, segue la notizia dell'arrivo del re Casimiro di Polonia, per onorare il morto, e il racconto delle cerimonie svoltesi per il trigesimo.

La narrazione dei riti funebri per Carlo I contiene molti elementi che sembrano riconducibili non solo alla personalità del re, ma anche alla sua cultura e alla natura del suo potere monarchico. La lunghezza delle celebrazioni, il numero e l'autorevolezza dei partecipanti, l'aulica retorica all'antica del compianto, costituiscono in effetti lo sfondo necessario alla messa in scena di un rito che non poté non impressionare gli osservatori. Se anche le lacrime corsero in quell'occasione così copiose da impedire di vedere bene quanto succedeva, come afferma il cronista, è pur vero che tutto l'apparato fu concepito per illustrare in quadri viventi altamente simbolici la potenza del re morto, per esaltarne il regno, per accrescere il consenso verso la dinastia di quel re che più di quarant'anni prima era giunto da Napoli per essere incoronato con la corona di santo Stefano.

\section{IL VOLTO SCOPERTO DEL RE E IL RUOLO DEI REGALIA}

Nella descrizione del funerale di Carlo I vi è un elemento che dové colpire molto l'autore del resoconto (e con lui, gli altri partecipanti e spettatori dell'evento), che per enfatizzarne la novità chiamò in causa antiche fonti scritte che testimoniassero la consuetudine fino ad allora invalsa in Ungheria di velare il re defunto ${ }^{19}$ : mi riferisco al fatto che la testa di Carlo I rimase esposta agli sguardi durante tutte le celebrazioni, contro la prassi tradizionale dei re ungheresi. Lasciare scoperto il volto del re era di certo funzionale all'accertamento pubblico della sua morte, indispensabile per la legittimazione della successione al trono, ma nello stesso tempo aggiungeva al cerimoniale funebre un dato inedito,

\footnotetext{
${ }^{18}$ Sui re-santi ungheresi: G. KLANICZAY, Holy Rulers and Blessed Princesses. Dynastic Cults in Medieval Central Europe, Cambridge, 2002; più in generale: La royauté sacrée dans le monde chrétien, Actes du colloque (Royaumont, mars 1989), sous la direction de A. BOUREAU et C.-S. INGERFLOM, Paris, 1992. Per un sintetico sguardo storiografico su questo tema: C. MERCURI, La regalità sacra nell'Occidente medievale: temi e prospettive, in Come l'orco della fiaba. Studi per Franco Cardini, a cura di M. MONTESANO, Firenze, 2010, pp. 449-459.

${ }^{19}$ Nelle due uniche miniature del Chronicon pictum in cui si assiste a un seppellimento di un re o a un funerale reale - la vignetta con Ladislao morto sul carro funebre (fig. 5) e quella con la tumulazione di Maria, prima moglie di Carlo I (fig. 6) - i volti dei personaggi sono scoperti: nella prima, Ladislao reca lo scettro e il globo, ma non la corona, sostituita dal nimbo alludente alla sua futura santità; nella seconda, Maria, già nel sarcofago, indossa abiti solenni e la corona di regina.
} 
più volte invece attestato per i re di Francia ${ }^{20}$, quegli stessi re dai quali Carlo I era ben consapevole di discendere, come illustravano i gigli capetingi sulle sue insegne araldiche ${ }^{21}$.

Sul capo del re era stata posta, inoltre, una corona d'oro: che questa corona non fu tolta al momento del seppellimento è dimostrato da un documento del 1349, nel quale il re Ludovico il Grande rendeva noto che gli arcivescovi del regno, insieme a molti baroni e prelati, avevano condannato al carcere perpetuo Giovanni, il custode della chiesa di Alba Reale, per aver denudato il cadavere del re e sottratto la sua corona d'oro, opera magnifica; in conseguenza di ciò, il possedimento di Gyogh, "in comitatu Simighiensi", appartenuto al colpevole, era donato da Ludovico a sua madre Elisabetta ${ }^{22}$. Secondo l'editore ottocentesco del Chronicon Budense, Joseph Podhradczky, la corona posta sul capo del re durante il funerale e poi nella tomba doveva essere quella fatta realizzare da Gentile Partino nel $1309^{23}$. La commissione di questa corona aveva costituito, a mio parere, uno degli assi che il cardinale francescano aveva posto sul tavolo di gioco durante la sua missione diplomatica in Ungheria, una sorta di colpo da maestro, che avrebbe potuto riuscirgli se non si fosse trattato proprio dell'Ungheria, ma che non gli riuscì fino in fondo.

Quando Gentile era arrivato a Buda nel 1308 per mettere in piedi l'incoronazione di Carlo I e chiudere il periodo di torbidi in cui versava il paese, la corona detta di santo Stefano - e proprio perciò considerata sacra - si trovava nelle mani del vovoida di Transilvania, László, che si rifiutava di consegnarla persino al legato papale. Senza questa corona, condizione essenziale della cerimonia che "secundum usum" doveva svolgersi nella chiesa di Alba Reale, qualsiasi incoronazione sarebbe stata giudicata illecita dall'aristocrazia ungherese e avrebbe vanificato tutti gli sforzi compiuti da Gentile per trovare un accordo con gli oppositori di Carlo I. Fu per tali ragioni, connesse a un rituale che né il sovrano venuto da Napoli né l'emissario papale avrebbero mai potuto modificare, che Gentile aveva fatto benedire, l'11 giugno 1309, dal vescovo Tamás di Esztergom, una nuova corona, d'oro e di pietre preziose, appositamente realizzata in sostituzione della corona di santo Stefano ${ }^{24}$. Per legittimare l'uso di questa corona, Gentile era stato anche obbligato a includere un capitolo sulla "corona regis" nelle Costituzioni sinodali da lui emanate in nome di Clemente V tra l'8 maggio e il 14 luglio

\footnotetext{
${ }^{20}$ La pratica di lasciare scoperto il volto del re defunto, dotato di corona e di insegne regali, per tutta la durata dei funerali, anche se questi si protraevano per più giorni, viene fatta risalire al re Enrico Plantageneto, sepolto nel 1189 a Fontevrault vestito degli abiti indossati durante la consacrazione reale. Quando Filippo IV il Bello morì nel 1314, il suo volto rimase privo di qualsiasi copertura fino alla sepoltura a Saint-Denis, com'è attestato da un resoconto contemporaneo, ma Filippo $\mathrm{V}$ nel $1322 \mathrm{fu}$ portato in processione con il volto coperto da un drappo e allo stesso modo fu calato nella tomba: Ch. BAUDON DE MONY, La mort et les funérailles de Philippe le Bel d'après un compte rendu à la cour de Majorque, in Bibliothèque de l'École des chartes, 58 (1897), pp. 5-14; R. GIESEY, The Royal Funeral Cerimony in Renaissance France, Genève, 1960, pp. 22-24; A. ERLANDE-BRANDENBURG, Le roi est mort, étude sur les funérailles, les sépultures et les tombeaux des rois de France jusqu'à la fin du XIII' siècle, Genève, 1975, pp. 15-22; E. BROWN, The Ceremonial of Royal Succession in Capetian France: The Funeral of Philip V, in Speculum, 55 (1980), pp. 266-293. Sul trattamento del corpo dei re francesi: EAD., Death and the Human Body in the Later Middle Ages: The Legislation of Boniface VIII on the Division of the Corpse, in Viator, XII (1981), pp. 221-270; in relazione a san Luigi: V. LUCHERINI, Smembrare il corpo del re e moltiplicare le reliquie del santo: il caso di Luigi IX di Francia, in Convivium. Exchanges and Interactions in the Arts of Medieval Europe, Byzantium, and the Mediterranean. Seminarium Kondakovianum Series Nova, I/1 (2014), pp. 88-101.

${ }^{21} \mathrm{Si}$ osservi anche che mentre nei documenti redatti da Gentile Partino di Montefiore si sottolinea quasi esclusivamente la discendenza di Carlo I dai re d'Ungheria, strumentale all'insediamento sul trono ungherese di un re straniero, in una lettera del papa Benedetto XII del 1338 indirizzata proprio a Carlo I si citano invece a chiare lettere i "progenitores tui, catholici reges et principes regnorum Franciæ, Siciliæ et Hungariæ, de quorum claro germine processisti": Historia critica regum Hungarice stirpis mixtce ex fide domesticorum et exterorum scriptorum concinnata a Stephano Katona, aa., Il. et philos. doctore, presbytero Strigoniensi, tomulus II, ordine IX, ab anno Christi MCCCXXXII ad annum MCCCL, Budæ, MDCCXC, p. 133.

${ }^{22}$ Gy. FEJÉR, Codex diplomaticum Hungarice ecclesiasticus et civilis, cit., IX/1, pp. 644-647.

${ }^{23}$ Chronicon Budense, cit., p. 259 e nota 1.

${ }^{24}$ Prcelati regni Hungarice Carolum regem corona nova, per cardinalem Gentilem benedicta, coronatur esse testantur (Arch. Vat. C. fasc. 40, nr. 8), in: Monumenta Vaticana, cit., pp. 352-356 (doc. LXVIII).
} 


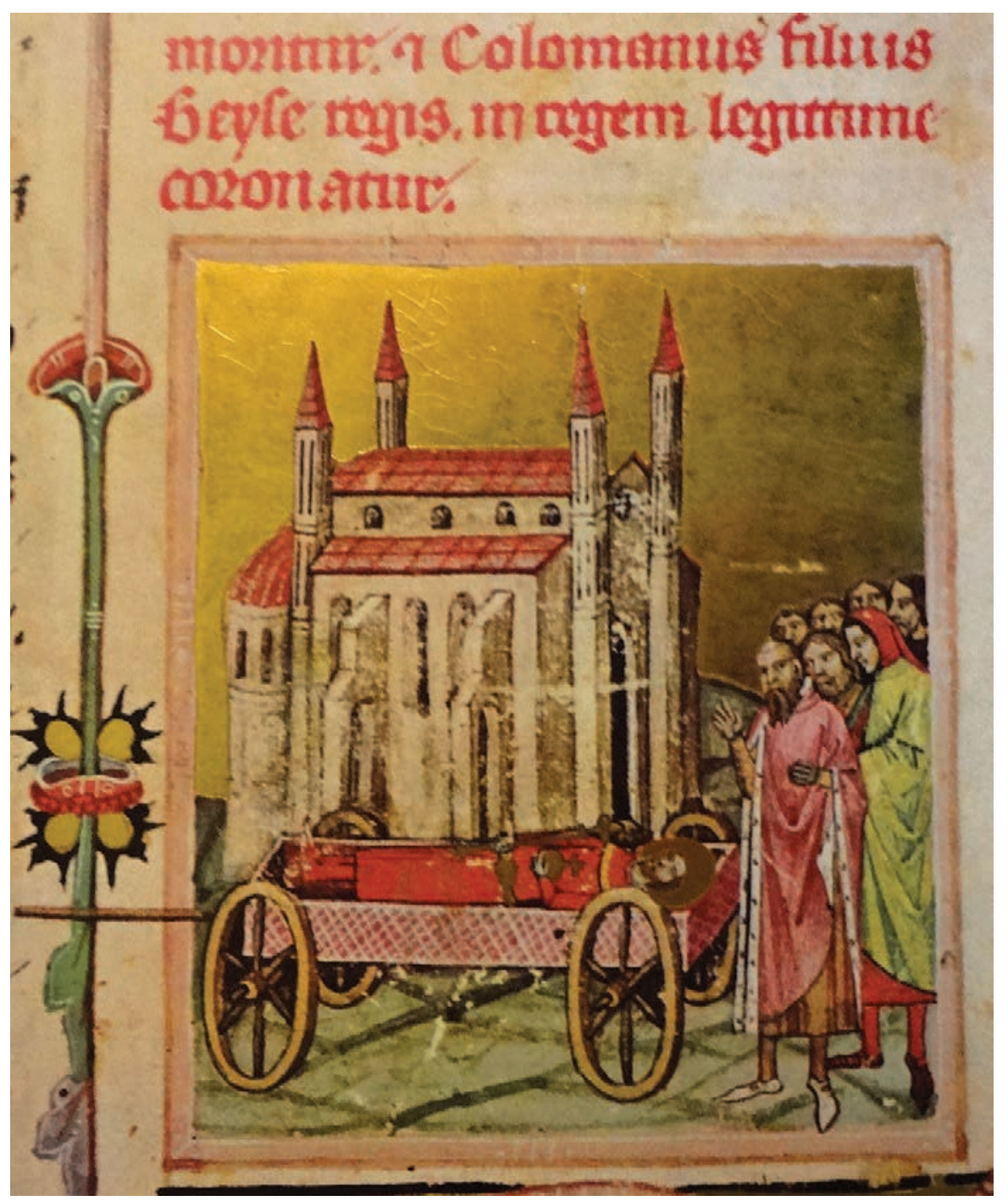

Fig. 5. Budapest, Országos Széchényi Könyvtár, Clmae 404, Chronicon pictum, fol. 51r, Funerale del re Ladislao.

1309, nel quale sanciva l'uso di una corona surrogata qualora quella di santo Stefano non fosse stata disponibile $^{25}$. La mossa non ebbe però l'effetto desiderato, tanto che dopo un'incoronazione con la corona sostitutiva svoltasi il 15 giugno 1309 a Buda ${ }^{26}$, Carlo I dové essere nuovamente incoronato re, ad Alba Reale, con la corona di santo Stefano il 27 agosto 1310, secondo la prassi ungherese in vigore da secoli, l'unica sulla quale poteva fondarsi la sua autorità regia.

Non abbiamo prove per sostenere che la corona nella tomba sia stata proprio quella commissionata da Gentile Partino, o non sia stata piuttosto un'altra corona ugualmente preziosa, ma un dato emerge chiaro dalla documentazione testuale conservatasi. Il funerale di Carlo I si svolse utilizzando tutto l'apparato scenico di un sacré royal, ponendosi come l'ultimo episodio pubblico di una lunga vita al governo del Regno d'Ungheria e chiudendo un ciclo iniziato con la sua incoronazione: il ceri-

\footnotetext{
${ }^{25}$ Ibidem, pp. 273-275 (doc. LXI).

${ }^{26}$ Carolus rex Hungarice presentibus cardinale Gentile ac proelatis et baronibus iuramentum de conservatione iurium eiusdem regni prostat. (Arch. Vat. C. fasc. 40, nr. 7), in: Monumenta Vaticana, cit., pp. pp. 304-307 (doc. LXV). Per l'analisi complessiva dei tre documenti citati: V. LUCHERINI, The Hungarian Constitutiones Synodales of 1309 and the "Holy Crown": The Theological Use of an Art Object as Political Symbol, in: Medieval and Early Modern Political Theology: Theory and Practice, edited by J. AURELL and M. HERRERO, Leiden, 2015, in corso di stampa.
} 


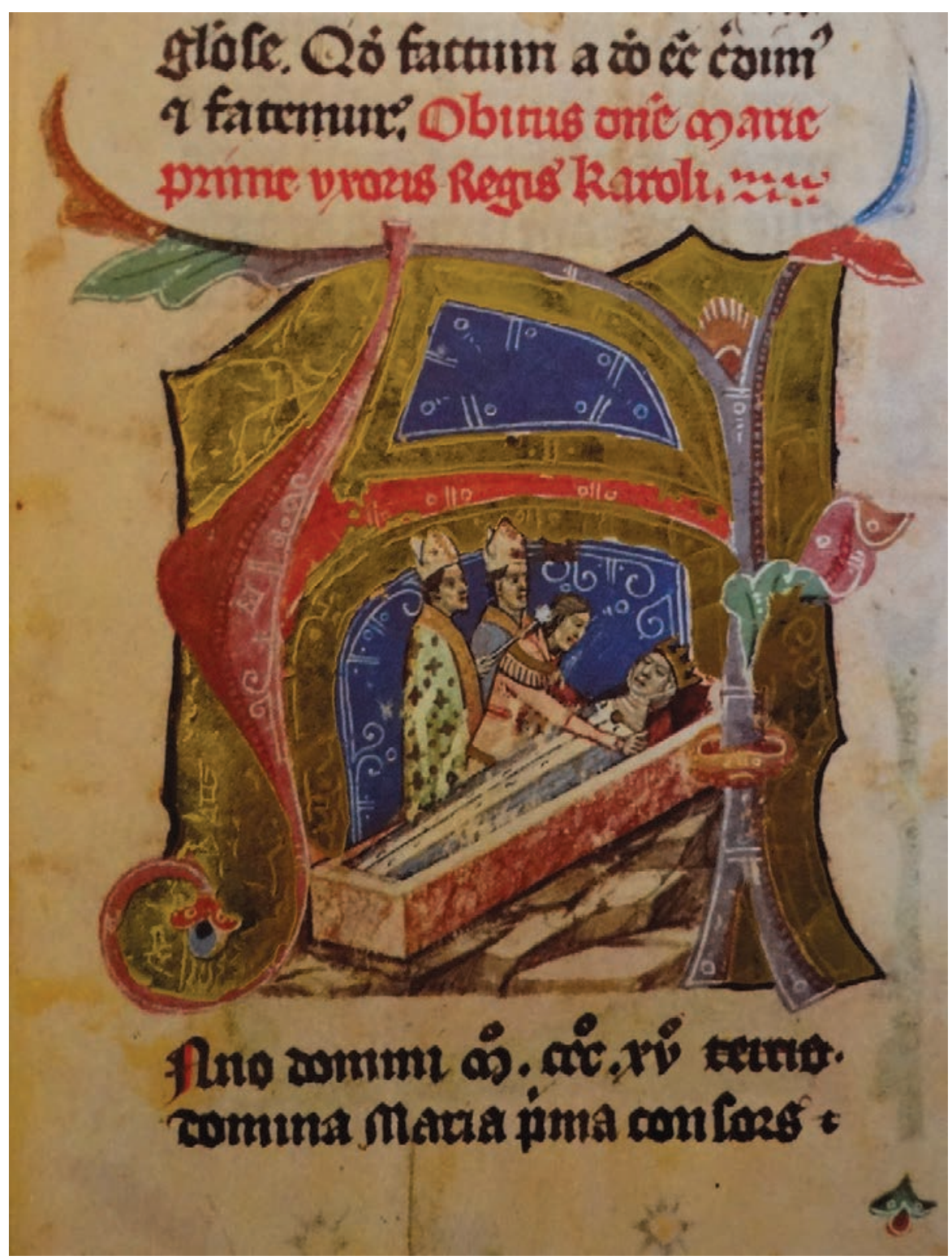

Fig. 6. Budapest, Országos Széchényi Könyvtár, Clmae 404, Chronicon pictum, fol. 70r, Tumulazione della prima moglie di Carlo I.

moniale che seguì la sua morte sanciva che Carlo I doveva essere a tutti gli effetti considerato "verum et legitimum regem Hungariæ ac dominum naturalem", in quanto "ex primorum sanctorum regum vera progenie propagatum", secondo le parole usate da Gentile Partino nel suo dossier diplomatico. Questo implicava anche che l'allora primogenito Ludovico, rimasto tale dopo la morte dei primi due fratelli, avrebbe potuto accedere al trono ungherese in quanto legittimo discendente di un re che da molto tempo non era ormai più considerato un napoletano, uno straniero nel regno.

\section{GLI IDEALI CAVALLERESCHI DEL RE E L'ARALDICA MESSA IN SCENA}

Nella descrizione del funerale di Carlo I c'è ancora un elemento che merita attenzione: il riferimento ai tre grandi cavalli del re, bardati sontuosamente, che ricorre tre volte nel passo. Una prima volta, come abbiamo visto, i cavalli sono descritti stanti davanti alle porte della chiesa di Buda nella quale si svolsero le cerimonie funebri, montati da cavalieri rivestiti delle armi e delle insegne araldiche del re: il cronista illustra la scena usando un lessico relativo all'equipaggiamento dei cavalli molto ricco, 
che non trova altrove paralleli linguistici ${ }^{27}$. Una seconda volta i cavalli sono detti sostare davanti alle porte della chiesa di Alba Reale, dove Carlo I fu tumulato accanto ai santi-re suoi predecessori, e il cronista pone l'accento ancora una volta sui reali ornamenti purpurei che li rivestivano. Una terza volta i cavalli sono citati in relazione ai ricchi donativi fatti alla collegiata di Alba Reale, per rinnovare la memoria del re. In quest'ultimo caso, non solo si sottolinea di nuovo la presenza delle armi di Carlo I su di essi, ma vi si collega anche un carro regale, mobile, forse sospeso con l'ausilio di catene ${ }^{28}$, sul quale ugualmente si stagliava l'insegna del re, lo struzzo.

Malgrado l'impossibilità di interpretare al momento con esattezza l'aggettivo "sartaneus" connesso al carro, sempre che la lezione di entrambi i testi a stampa che lo hanno tramandato (il Chronicon Budense e la Chronica Hungarorum di Thuróczy) sia esatta ${ }^{29}$, e malgrado che il carro compaia nella narrazione soltanto nell'elenco dei regali donati ad Alba Reale, non si può escludere che si trattasse di un carro con baldacchino, nel quale la parte superiore, forse in tessuto, recava la forma araldica dello struzzo in oro decorato di gemme. L'ulteriore precisazione del cronista a proposito di "notulis globaribus" d'argento dorato forse si potrebbe correggere in "rotulis globaribus", che sebbene ridondante potrebbe alludere a degli elementi ornamentali di forma circolare pendenti dalla parte superiore del baldacchino. Tenendo conto che l'uso di baldacchini e di stoffe decorate con le insegne dei re defunti è documentato già per la Francia medievale (basti pensare al funerale di Filippo V nel 1322) ${ }^{30}$, si potrebbe anche dedurre che il carro era servito a trasportare il corpo di Carlo I durante le processioni, forse al posto di una lettiera sorretta a braccia.

Nel parlare della posizione dei destrieri del re davanti alla chiesa di Buda, il cronista aveva inoltre già fornito un ulteriore particolare visivo degno di interesse: i cavalli e i loro cavalieri erano coperti, in alto, con pitture bellissime, ornate di porpora, gemme e pietre preziosissime. Se leggiamo attentamente il passo, e lo immettiamo nel suo contesto narrativo, ci accorgiamo che a queste pitture, forse esposte su un baldacchino di parata, una struttura finalizzata a proteggere ma anche a enfatizzare i cavalli del re sullo sfondo della facciata della chiesa, era assegnato un forte valore simbolico, perché chiunque, di qualsiasi condizione, guardandole, e soprattutto vedendovi le insegne reali, avrebbe pensato che Carlo I ancora governava felice il Regno d'Ungheria. Le armi di Carlo I, partite di Francia e d'Ungheria, e accompagnate dallo struzzo, disseminate sui cavalli, sui cavalieri e sulle pitture che li coprivano entrambi, avevano dunque il potere di convincere gli spettatori dolenti a credere che il re fosse ancora vivo.

Il cronista ci dà qui un esempio formidabile di come la divisa araldica di un re ne potesse proiettare simbolicamente l'essenza vitale più intima, sia pure di fronte a un cadavere con il volto scoperto che pure si ergeva a testimone tangibile della morte. Quel che sembra poi ancora più interessante ai fini di questo discorso è che questo procedimento di riproduzione visuale della natura del re morto attraverso i suoi simboli araldici si associa inscindibilmente nel racconto, e quindi nell'effettivo rituale del funerale di Carlo I, con i suoi tre monumentali cavalli e i loro altrettanto impressionanti cavalieri ${ }^{31}$.

\footnotetext{
${ }^{27}$ Come evidenziato nel Glossarium medice et infimce latinitatis, éd. augm., Niort, 1883-1887, t. 6, col. 432a, a proposito, ad esempio, del lemma "postena".

${ }^{28}$ La forma del carro è stata oggetto di diverse osservazione da parte degli specialisti di questi temi: J. MULBY, From Carriage to Coach: What happened, in: The Art, Science, and Technology of Medieval Travel, edited by R. BORK and A. KANN, Burlington, 2008, pp. 41-54.

${ }^{29}$ Glossarium mediae et infimae latinitatis, cit., t. 7, col. 313c., propone di leggere questo lemma come "sambuca", ma non sembra convincente.

${ }^{30}$ E. BROWN, The Ceremonial of Royal Succession, cit.

${ }^{31}$ Una "sambuca cum arczoneriis de argento, streugis tribus de argento, freno de argento, cum munitione loreni et pectoralis de argento deaurato, smaltatæ ad arma Franciæ et Ungariæ", dunque con in vista lo stemma partito con i fiori di giglio capetingi, usati dai re di Napoli con la brisura del lambello, e le fasce arpadiane, appartenuta probabilmente a Carlo Martello, padre di Carlo I, è attestato nell'inventario degli esecutori testamentari di Maria d'Ungheria, stilato il 31 maggio 1326 a tre anni dalla morte della regina: V. LUCHERINI, Il "testamento" di Maria d'Ungheria, cit.
} 
Non si può non ricordare, a tal riguardo, che fu proprio questo re a fondare in Europa il primo e più antico ordine cavalleresco non religioso creato da un sovrano: l'Ordine di San Giorgio, o più correttamente, secondo la definizione del documento che ne conserva lo statuto, datato 24 aprile 1326, la "societas fraternitatis militiæ sancti Georgii"32.

La descrizione dei cavalieri dotati di armi da torneo e dei cavalli dei re, con il loro corredo di pitture e immagini araldiche, è uno dei passaggi più significativi del testo relativo al funerale di Carlo I. Non solo chi la redasse doveva aver visto con i propri occhi quella scena, che dové suscitare sorpresa e meraviglia negli astanti, ma le dedicò uno spazio considerevole nell'economia della narrazione, come se i tre cavalli e i loro superbi cavalieri esprimessero al più alto grado, nello sfarzo dei simboli araldici, la maestà e la potenza del re defunto.

Sul rapporto tra cavalleria e araldica: M. PASTOUREAU, L'art heraldique au Moyen Âge, Paris, 2009; sull'uso principesco del cavallo: Le cheval dans la culture médiévale, textes réunis par B. ANDENMATTEN, A. PARAVICINI BAGLIANI e E. PIBIRI, Firenze, 2015. Sul valore narrativo delle immagini contenenti elementi araldici: X. BARRAL I ALTET, Forme di narrazione medievale, con o senza "storie», al servizio del potere, in Hortus artium medievalium, XXI (2015), pp. 6-20.

${ }^{32}$ Magyar Nemzeti Levéltár Országos Levéltára, Diplomatikai Levéltár [Archivio Nazionale Ungherese, Archivio diplomatico], 40483; può leggersi a stampa in G. FEJÉR, Codex diplomaticus Hungarice ecclesiasticus ac civilis, cit., VIII/3, pp. 163-170; Anjou-kori oklevéltár. Documenta res Hungaricas tempore regum Andegavensium illustrantia, a cura di T. ALMÁSI, L. BLAZOVICH et alii, Budapest-Szeged, 1990, X, n. 151. Per l'interpretazione di questo documento, che non è detto risalga all'epoca di fondazione dell'ordine: L. VESZPRÉMY, Az Anjou-kori lovagság egyes kérdései [Alcune questioni relative alla cavalleria in epoca angioina], in Hadtörténelmi Közlemények, 107 (1994), pp. 3-20, ripubblicato con alcune modifiche in IDEM; Lovagvilág Magyarországon [Il mondo dei cavalieri in Ungheria], Budapest, 2008, pp. 171-186; IDEM, L'ordine di San Giorgio, in: L'Ungheria angioina, cit., pp. 265-282. Sul sigillo originale che accompagna la carta: Münészet I. Lajos király korában [Arte nell'epoca di Ludovico I], edited by E. MAROSI, M. TÓTH, L. VARGA, Budapest, 1982, p. 148; Gy. RÁCZ, P. LOVEI, Acte de fondation de l'ordre de Saint-Georges avec le sceau de l'ordre, in Sigismundus. Rex et imperator. Art et culture au temps de Sigismond de Luxembourg 1387-1437, sous la direction de I. TAKACS, Budapest-Luxemburg, 2006, p. 337. Sugli ordini cavallereschi, in generale: D'A. J. D. BOULTON, The Knights of the Crown. The Monarchical Orders of Knighthood in Later Medieval Europe, 1325-1520, London, 1987. 


\section{Appendice $^{33}$}

\section{IL COMPIANTO DELL'ARCIVESCOVO CHANÁD DE THELEGD PER CARLO I D'UNGHERIA}

"Heu me! Quia huius mundi decus et gloria a primævo temporis spatio nunquam in uno statu permanens, sed semper variando versaliter atque caduce se protendens in nihilum, tamquam aqua decurrens incedit, nam omnia, quæ a terra gremio usque ad circumferentias cœli ambitu orbis continetur, dilabuntur in terram. Et quia nec ulli, mors impia parcendo nullaque pacis conditione simulando miseratur, cadit vita humana præ timore ipsius, dum stare putatur quali flos et protinus aret.

O mors! Quæ per excessus delictorum, veteris parentis protoplasti, morsu pomi noxialis, diabolicæ fraudis instigante nequitia præconcepta, serpentino veneno, virus iniquitatis infundens in orbem terræ, filios eiusdem protoplasti impavida non timens neque verens, dolo fraudis repeta, diripiendo intrandi semitas primitus quæritasti: mirum est quod tanta gulositate insatiabili cadavera mortuorum deglutiendo non satiaberis. Et cur de corpore foedissimo mortuorum quam vivorum congaudendo gratularis? Non enim ad domum convivii et cuiuslibet solennitatis festum, sed ad locum luctus plus festinas temere properare, neque casas pauperum, neque aulas seu atria regum, nullo nuntio mendiante, adire formidas, nec non conjugatos ex vera dilectione matrimoniali invicem copulatos, divortionis vinculo innodare pavescis, filium a patre, patrem a filio separando.

Nonne amaram, duram, crudelem et impiam te fore ostendebas, dum anno Domini MCCC quadragesimo secundo, sequenti die divisionis Apostolorum, XVIII Kalendas Augusti, castrum fortissimum inæstimabilis altitudinis et muros eiusdem inexpugnabilis, cui nec vis nec potentia huius mundi poterat quoquo modo dominari, tuæ vulpinæ dolositatis astutia clandestine, invisibiliter, introire non expavens et ibidem hostilitatis arma in anima potentissimi principis domini Caroli, Dei gratia regis Hungariæ, cuius potentia altissimo taliter disponente Dalmatia, Croatia, Rama, Servia, Gallicia, Lodomeria, Cumania, Bulgaria, totaque Hungaria, Salernaque (sic) ac mons Sancti Angeli, alia quoque regna, puta, Poloniense, Bohemiense, Austriense, ac circumquaque adiacentia, trepitanto abhorrebant, immettere non metuens ipsum quadraginta duobus annis et non pluribus vitæ comitem regnare permisisti, sed acriter tua dolositate consueta de medio regnicolis manifeste cernentibus felicissimæ recordationis pium regem nostrum famosissimum, non gazis ac pretiosis vestimentis, gemmis et pretiosis splendidis margaritis adornatis, auro et argento desuper contextis, sed spiritu vivificato spoliando subtraxisti, et ipsius splendentes honores in nihilum in terram humando obumbrasti.

Novissime vero, videntes ipsum regnicolæ esse pium ac exaltatum sicut cedrum Libani transeuntibus et quærentibus eum suis regnicolis, et ecce non erat. Ideo, propter tuum grande factum nefarium, omnibus revera dilectissimi catholice fidei cultoribus, pariter fidelitati semitarum adhærentibus, pium est, hunc ipsum dominum regem Carolum flere et ipsius morti, proh dolor!, lamentabiliter condolere. O quantus fletus, quanta lamenta prælatorum, procerum, baronum, nobilium, virginum, dominarum et cuiusvis status et conditionis hominum, specialiterque dominæ Elizabeth, serenissimæ reginæ, charissimæ consortis eiusdem, et domini Lodowici, nunc regis, ac Stephani ducis, filiorum eius. $\mathrm{O}$ quis considerasset et considerare antea præmeditando debuisset, quod tam inneffabile gaudium et hilaritas vultus scilicet serenissimæ dominæ reginæ tam crudeliter asperitate lachrymarum sit iam mutatus et, rivulis gurgitum ad instar aquarum ob oculis eiusdem usque ad terram a tempore obitus ipsius incessanter currentibus, humefactus et organica vox, clamoris et gemitus eiusdem et suorum regnicolarum ad orbis cœli summitatem perveniendo, æthera quasi compati compulerit, in tantum, ut sol, sui optimi coloris radis plurimum visus fuerit obfuscare".

\footnotetext{
${ }^{33}$ La trascrizione del testo, che qui si pubblica con una revisione della punteggiatura che renda più agevole la lettura, è basata sull'edizione della Chronica Hungarorum di Thuróczy edita negli Scriptores rerum Hungaricarum veteres et genuini, partim primum ex tenebris eruti, partem antehac quidem editi, nunc vero ex mms. codicibus et rarissimis editionibus Bibliothecoe Augustoe Vindobonensis ab innumeris mendis vindicati, plurimis variantibus lectionibus et necessariis hinc inde quibusdam notis illustrati, et cum amplissima proefatione Mathice Belli, cura et studio Joannis Georgii Schwandtneri Austriaci Stadelkirchensis, parts prima, Tyrnaviæ, Typis Collegii Academici Societatis Jesu, anno MDCCLXV, pp. 270-277.
} 


\section{LA DESCRIZIONE DEL CERIMONIALE FUNEBRE E DELLA SEPOLTURA DI CARLO I D'UNGHERIA}

"Tandemque die sequenti, ob præceptum dictæ dominæ reginæ [Elizabeth], archiepiscopis, episcopis, prælatis, baronibus, presbyteris, fratribus, clericis omnibus, simul convenientibus, et lachrimabiliter processive pergentibus, ad dictum castrum devenitur, ubi pretiosisimum caput eius, iuxta decentiam regni sui honoris, corona aurea corpusque ipsius splendidissimum tunica scarletina ac etiam caligis, salutaribus gemmis pretiosissimis contextis, et desuper calcaria aurea pulcherrimis pedibus suæ excellentiæ annectendo induentes, de prædicto castro inexpugnabili, in ecclesiam parochialem Virginis Gloriosæ in Wyssegrad civitate constructam, planctu magno deferebant. Planxitque eum universus populus civitatis planctu magno valde.

Peractis autem ibidem divinis institutionibus et missarum solennibus, corpus ipsum super cimbam per decursus aquæ Danubialis in civitate famosissima, Budam videlicet, est delatum. Antecedebant autem flebiliter ipsam multitudinem prælatorum, baronum et regnicolarum, et vexillo triumphali miles famosissimus atque manu fortis, Laurentius Sclavus, cuius intererat tempore vitæ ipsius domini regis ex officio eidem incumbenti, vexilla regalia ferre, loco opportuno, ubi omnes cives dictæ civitatis famosissimæ, sacerdotes et clerici, ac viri religiosi, ipsamque inhabitantes alii, processive pergentes, condolendo oculis lachrimantibus, vestimenta lugubria portantes, obviam ipsius corpori usque ad Danubium processerunt. Et dum in dictam civitatem adduxissent, supra corpus ipsius cantica psallere et alia divina officia, ut mos est pro expiratis eorundem, per totam noctem preces offerre cantando non cessant summo creatori; tertio autem die obitus ipsius, in eadem civitate, medio temporis spatio, quousque divina officia vel mysteria incepta, et missarum solennitates modo debito peragerentur.

Tres solennes dextrarii ipsius domini regis Karoli, suis phalerati purpureis operimentis, super quos milites strenui armis eiusdem domini regis induti sedebant, ante fores ecclesiæ steterunt. Quorum quidem militum unus armis tormentalibus, regiæ excellentiæ convenientibus, erat ornatus; et alter, ad hastiludium aptus; tertius vero armis bellicis, regiæ maiestati competentibus, erat circumseptus. In quorum quidem militum, dictis regalibus equis insidentium, galeis aureis, coronis circumdatis, insignia, sub forma struthionis avis, quæ per ipsum dominum regem vita sibi comite haberi et ferri consueverant, habebantur. Universa namque ferramenta, streparum et habenarum, seu rudibularum, et alia ad ipsum spectantia de argento inaurato iuxta decentiam regiæ excellentiæ, fabricata existebant; corrigiarumque cinguli et frena, ac similia alia, cum thenis et postenis sericæ substantiæ contexta fuerant. Nobilissimis namque picturis purpureis, gemmis et lapidibus pretiosissimis, dicti trini dextrarii et miles, in persona et spiritu eiusdem domini regis, super ipsos tegebantur, quos ut, dum cuiuscumque conditionis homines aspiciebant et dicta signa regalia intuebantur, eo quod idem dominus rex hactenus imperium regni Hungariæ, habitis præmissis signis et dextrariis, feliciter gubernavit, mox prorumpebant in fletus, validissimis æthera ululatibus propulsantes.

Peractis tandem divinis institutionibus et missarum solennitatibus, non more aliorum quorundam regum, dudum defunctorum, quos felicissimæ recordationis scripturæ aliarum epistolarum venerabilis commendat auctoritas, velata facie, nec corpore eius alicuius diei spatio celato, prout abusiva consuetudo, aliis vicibus quorundam regum funeribus perhibetur astruxisse, sed manifeste omnibus præsentibus facie ad faciem manifeste cernentibus, ad Albam civitate, deferebatur dictum corpus tumulandum. Inde autem ferendo corpus ipsius ad quamcumque mansionis villam deveniebat, omnes homines tam viri quam mulieres, lachrymarum fletu condolentes, clamore maximo in amaritudinem conversi æthera propulsando, resonabant. Dumque ad Albensem civitatem dictum corpus pervenire nitidissimum modo quo superius allegatur, prælati, presbyteri, clerici aliique regnicolæ ac cives dictæ civitatis extra civitatem celeriter pergentes, ipsumque corpus vivificato spiritu spoliatum amarissime circumspicientes, in inenarrabiles fletus eo viso prorumpentes, illud intra civitatem detulerunt. Illi quoque sacerdotes et clerici per totam noctem hymnos et psalmos deo decantantes, in vigiliis pausando, deduxerunt noctis prolixitatem. Dieque lucescente, inceptis divinis et missarum solennitatibus, quousque divina mysteria incepta et missarum solennitates more debito, eodem die peragerentur, antedicti trini dextrarii ipsius domini regis, modo præmisso, phalerati, purpureisque 
cooperimentis decorati, super quos præfati milites strenui arma eiusdem domini regis induentes ante fores ipsius monasterii, ut est præmissum, steterunt perdurantes. Et demum, eisdem digne compleris et consummatis quæ in eodem die celebrari debebant, in summo monasterio, ubi sanctissimi regis Stephani et Emerici ducis, filii eius, sanctissima corpora, diversis coruscantia virtutibus et miraculis, in Domino feliciter requiescunt, et summa pietatis opera ipsa benigne implorantibus, misericorditer partiuntur, iuxta altare magnum, in vestimento regali ad hoc sibi debito, per prædictos enarratos dominos et archiepiscopos, episcopos, prælatos et abbates, sacris vestimentis indutos, extitit tumulatum, et omnes unanimiter planxerunt eum, simul unum dives et pauper, in tantum ut marmoreis lapides, densitate lachrymarum, plurimum fuerint humefacti. Tunc enim tam maximo clamore gemebundi omnium circumstantium fauces raucæ factæ sunt, oculique ipsorum præ tantys lacrymis visibus naturalibus fere defecerunt.

Ubi etiam venerabilis in Christo pater, dominus Chanadinus, Strigoniensis archiepiscopus, de obitu ipsius regis, salubri ac pio sermone, intentos animos et pia corda circumstantium, linivit condecenter. Cuius quidem lachrymositatis et inenumerabilis moestitiæ prætextu, creditur eos qui reges tumulari non conspecerunt, de acerbitate doloris instillationeque lachrymarum, quasi imparticipes et inscios fore et extare. Attamen non mirum quod omnes creaturæ, carne et pelle vestitæ, ut est prætactum, per lapsum veteris parentis protoplasti in culpam sint morituræ. Nam in omnem posteritatem, moriendi legem condidisse videtur generalem et incommutabilem, adeo ut altissimo, proprio filio suo, licet deitate vestito parcere noluit, sed pro nobis omnibus tradit illum. Non igitur quisquam indignando Creatori, propter factum mortis inevitabile, potest obviare, et qui non est sapientia neque prudentia neque fortitudo neque consilium contra Dominum, sed potius ferendus est gravis eventus necis patienter, quia quod donaverat Dominus accepit et in die illa surrecturum in ipso.

Tunc ibidem prædictum supremum monasterium cum aliis ecclesiis innumerabilibus muneribus regalibus et oblationum maximis quantitatibus extitit donando remuneratum. Et tandem antedicti trini dextrarii solennes, cum armis et operimentis omnibus ipsorum glorissimis seu attinentiis, cum sartaneo curru seu mobili aut ostiliario regnali signo regio desuper forma avis struthionis deaurato et gemmis adornato, cum septenis notulis globaribus argenteis et similiter deauratis, ob planctus memoriam ineffabilis et luctus amaritudinem jam dicti domini regis in posterum semper in memoriam revocandi, cum innumerabilibus supradictam quantitem pecuniis dicto monasterio dati et concessi extiterunt. Cuius quidem donationis et oblationis maxima quantitas ibidem die tumulationi facta, data et concessa in præsenti scriptura seriatim non ponitur, ne calamis scriventium pariter legentibus fastidium multiplicationis generaret sua prolixitate.

Deinde vero potentissimi regis obitum famosissimus rex Kazimirus Poloniæ proximus eiusdem et marchio Moraviæ in Wyssegrad venientes, condolenti animo celebraverunt. Demunque triginta diebus completis, quarta feria, proxima ante assumptionem Virginis gloriosæ, tricesimum diem ipsius regis Caroli cum magna solennitate missarum peracturi, ut superius extitit enarratum, prælati, episcopis cum baronibus quam pluribus, Albam, ubi corpus ipsius domini regis Caroli solenniter in Domino requiescens extiterat tumulatum, accedentes et ibique Albæ et in Wissegradiensi civitate domina regina cum filio suo Ludowico tunc rege coronato sibi prædilecto aliisque prælatis, episcopis, presbyteris, baronibus et plurimis Christi fidelibus, funeri obsequias devotissime celebrantur. Et totius regni universales etiam in toto regno diffusæ eodem solennitatis voto et missarum sollennitatibus dictum officium celebrantes compleverunt. Imploranda ergo est unanimi consensu clementia Dei omnipotentis pro eodem domino rege Carolo, ut cum anima ipsius clementer dispenset, eidem indulgendo et in numerum ipsius animam ac cœtus santorum confessorum omnium et regum Stephani et Ladislai dignetur collocare, et prout quod in præsenti seculo regali triumpho vixerit, ita etiam in futuro seculo cum angelis valeat exultare". 


\section{“NOBILISSIM/E PICTURAE PURPURE/E”: POGREB MAĐARSKOG KRALA KARLA I. (1342) I PROJEKCIJA VLADARSKE MOĆI U KASNOM SREDNJEM VIJEKU}

U članku se analizira opis pogrebnih obreda koji su se održali poslije smrti mađarskog kralja Karla I., 16. srpnja 1342. Opis je napisao netko tko je bio prisutan na obredima te je bio u mogućnosti vjerno opisati što se tih dana događalo. Prenošen samo preko petnaestostoljetnih mađarskih ljetopisa, ovaj opis je dokument od velike važnosti za proučavanje srednjovjekovnih rituala, pogotovo kad se uzme u obzir da su izvori ove vrste za srednjovjekovnu Europu veoma rijetki te da je teško napraviti usporedbu između različitih vrsta kraljevskih pogrebnih rituala. U tekstu se pripovijeda o tome kako se kralja Karla I. pripremalo za vjerske obrede. Kraljevo lice ostalo je otkriveno tijekom cijelog pogreba, kao što bio slučaj na mnogim sprovodima francuskih kraljeva u kasnom srednjem vijeku, dok je tijelo bilo prekriveno veličanstvenom odjećom dostojnom posvete, poput grimizne tunike. Glava je bila prekrivena zlatnom krunom. Opisani rituali stalno naglašavaju prisustvo kraljevih heraldičkih insignija. Na najznačajnijim mjestima cijele ceremonije, ispred crkve Gospe od Budima i ispred crkve u Alba Reale, stajala su tri kraljevska konja s tri jahača u punoj opremi s kraljevskim insignijama tako da je svatko tko ih je vidio mogao povjerovati da je kralj još uvijek živ. Ova viteška scenografija bila je popraćena prelijepim slikama, ukrašenim purpurom, gemama i dragim kamenjem. Kralj je zatim pokopan u danas nestalu mramornu grobnicu, u istoj crkvi u Alba Reale, gdje je bio i okrunjen 1310. Pogrebni ritual naglašavao je kraljevstvo i viteške vrline preminulih te tako pomagao legitimizaciji njegovog sina Ludovika kao nasljednika prijestolja.

Ključne riječi: Kraljevina Mađarska, kralj Karlo I., srednjovjekovni i humanistički ljetopisi, obredi moći

Prevela: Marija Bijelić 